\title{
Utilización de Leucaena leucocephala en el levante de ovinos africanos en el Piedemonte Llanero, Colombia
}

\section{Using Leucaena leucocephala in africans sheeps in the Piedemonte Llanero, Colombia}

\author{
Leguizamón L. A. ${ }^{1}$ Pérez C. A. ${ }^{2}$ y Roa M. L. ${ }^{3}$ \\ ${ }^{1} M V Z$., UNILLANOS, ${ }^{2} \mathrm{MVZ}$, SENA Hachón, Villavicencio, \\ ${ }^{3} Z$. MSc. Docente UNILLANOS, Villavicencio, Meta Colombia \\ mroa@unillanos.edu.co
}

Recibido 09 de Noviembre de 2009, aprobado 01 de Diciembre 2010

\section{RESUMEN}

El objetivo de este proyecto fue evaluar la L. lecucephala como suplemento en ovinos de levante en pastoreo. Se utilizaron 12 machos tipo africano (sudaneses), peso promedio de $14.45 \mathrm{Kg}$, con una dieta base de $B$. decumbens, los ovinos se distribuyeron completamente al azar tres repeticiones y cuatro tratamientos: $\mathrm{T} 1$ : (testigo) braquiaria, T2: braquiaria más el 1\% del peso vivo del animal, en materia seca de leucaena (MSL), T3: braquiaria, $1.5 \%$ de MSL y T4: braquiaria más el $2.0 \%$ de MSL. Los ovinos se mantuvieron en franjas divididas con cerca eléctrica y diariamente se rotaban. Los pesajes se tomaron cada 7 días durante los dos meses. Para las pruebas de digestibilidad, se utilizaron cuatro ovinos machos, peso promedio de 15 kilos y se estabularon en jaulas metabólicas, se les suministraron los mismos tratamientos para evaluar la digestibilidad in vivo. Al pasto braquiaria y a la leucaena se les realizaron análisis proximal (materia seca proteína, grasa, fibra cruda, cenizas) y determinación de fibra detergente neutro (FDN) y fibra detergente ácido (FDA). A las excretas recolectadas también se realizaron los mismos análisis de los forrajes, se calcularon los coeficientes de digestibilidad (COD) y los nutrientes digestibles totales (NDT). El contenido de proteína de la leucaena es de $19.3 \%$, mientras que la del pasto es de $8.5 \%$, es 2.29 veces más la de la leguminosa comparada con la del pasto. Las 
digestibilidades de MS y proteína fueron superiores $(P>0.05)$ en los tratamientos T3 y T4, con relación a los otros dos. Las ganancias de peso total y diaria fueron superiores $(P>0.05)$ para T3 seguido de T4 y T2 que son mayores $(P>0.05)$ a T1. Los consumos de MS fueron más elevados $(P>0.05)$ en T1 y T4 con relación a T3 y T2. La mejor conversión alimenticia $(P>0.05)$ sobre el consumo de MS fue para T3 seguido de T2, T4 y T1. Indudablemente, utilizar la leucaena para la alimentación de rumiantes como suplemento de una gramínea es ventajoso porque su contenido nutricional le permite ofrecer una dieta balanceada al animal sin detrimento de sus índices productivos, sobre todo en zonas donde los forrajes son de baja calidad.

Palabras clave: Arbustivas, suplemento, pastoreo, ganancia de peso, forraje.

\section{ABSTRACT}

The objective of this project was to evaluate the leucaena (Leucahena lecucephala) as a supplement in sheep grazing. Using 12 males African (Sudanese), average weight of $14.45 \mathrm{~kg}$, with a base diet of braquiaria ( $B$. decumbens), the sheeps were randomly distributed entirely to the three replications and four treatments: T1 (control): braquiaria, T2: braquiaria plus $1 \%$ of live animal weight of dry matter of leucaena (DML), T3 braquiaria, $1.5 \%$ of DML and T4: braquiaria plus $2.0 \%$ of DML. The sheep remained in bands divided with electric fence and were rotated daily. The sheeps were weigthed every seven days during the two months. In four sheeps, with a weight of $15 \mathrm{~kg}$ were housed in metabolic cages, were given the same treatments to assess the digestibility in vivo. At the braquiaria and leucaena were analyzed for estimate dry matter, protein, fat, Crude fiber, and ash, neutral detergent fiber (NDF) and acid detergent fiber (ADF) The collected excreta were also analized to determinate the same nutrients of the forages. With this information were calculated digestibility coefficients (COD) and total digestible nutrients (TDN). The protein content in leucaena is $19.3 \%$, while that of grass is $8.5 \% 2.29$ times that of the legume compared with grass. 
The digestibility of DM and protein were higher $(P>0.05)$ in T3 and T4, compared with the other two treatments. The total weight gains and daily were higher $(P>0.05)$ for T3 and T2 followed by T4 that are higher $(P>0.05)$ at T1. The DM intakes were higher $(P>0.05) \mathrm{T} 1$ and T4 and T3 compared with T2. The best feed conversion ( $P>0.05$ ) on DM intake was T3 followed by T2, T4 and T1. Undoubtedly, using leucaena fed to ruminants as a supplement to a grass is advantageous because its nutrient content allows it to offer a balanced diet without detriment to its productive indices, especially in areas where forages are of low quality.

Keywords: Shrub, supplement, grazing, weight gain, forage.

\section{INTRODUCCIÓN}

La leucaena (Leucaena leucocephala) se le conoce también como guaje, es originaria de América, se le considera una arbustiva de hojas bipinadas, con inflorescencias de color blanco, sus vainas son delgadas y pueden medir hasta $20 \mathrm{~cm}$ de largo y $2 \mathrm{~cm}$ de ancho y contienen de 15 a 25 semillas. Responde mejor en suelos profundos y negros, hasta una altura de 500 metros sobre el nivel del mar. Soporta inundaciones ocasionales, heladas leves y sequías. Su adaptación se dificulta en suelos ácidos. Esta leguminosa se viene utilizando fundamentalmente en la alimentación de rumiantes, cortina rompeviento y leña para construcción (Sosa et al.,1999).

Algunos resultados permiten afirmar que la leucaena junto a otras gramíneas y leguminosas pueden contribuir significativamente a transformar el panorama económico, productivo y ambiental de las zonas que presenten suelos degradados y ácidos húmedos e infértiles, lo que le confiere una plasticidad ecológica superior a la considerada hasta el momento, estas características la proyectan para proponerla como variedad comercial (Pérez et al., 2008). Debido a que la leucaena es una leguminosa ayuda a mejorar los recursos forrajeros Osehas et al. (2008), en estudios realizados en fincas con doble propósito ubicadas en 
Trujillo, Venezuela, cuyo objetivo fue conocer la manera como los ganaderos manejaban sus forrajes, encontraron que el $21.1 \%$ de las fincas usaban la leucaena, asociada con gramíneas o en cultivo solo. Las estrategias más utilizadas para el manejo de potreros fueron: Fertilización, análisis de suelos, rotación de potreros y control de malezas; con períodos de ocupación y descanso de 2 a 4 y 30 a 40 días respectivamente. El promedio de producción de leche fue

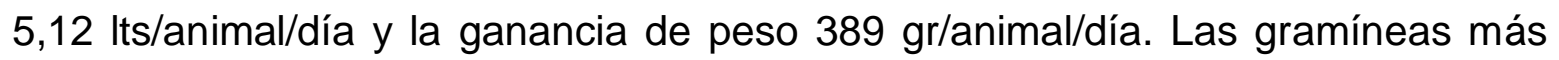
comunes fueron $P$. máximum y $C$. nlenfuensis. Respecto a esto, Ibrahim et al. (2007) reportan que en Cuba y Colombia se viene utilizando la leucaena en sistemas silvopastoriles, asociada con gramíneas, en ganadería doble propósito con buenos resultados.

Respecto a su calidad nutricional Cruz, (1999) menciona que la leucaena contiene: proteína 25.6\%, fibra detergente neutro (FDN) 31.7\%, fibra detergente ácido (FDA) $21.9 \%$, degradabilidad de la materia seca $80.3 \%$ y degradabilidad del nitrógeno total $52.2 \%$. Aunque contiene una sustancia tóxica llamada mimosina, los rumiantes no presentan ningún problema de salud, debido a que las bacterias del rumen degradan esta sustancia, utilizándola como fuente de nitrógeno.

García et al. 2008, evaluaron la composición nutricional de seis grupos cultivares: de L. leucocephala: 1 (L. leucocephala cv. CNIA-250 y K-28), 2 ( L. leucocephala cv. Ipil-Ipil), 3 (L. leucocephala cv. México), 4 (L. leucocephala cv. Cunningham, $L$. leucocephala cv. 7 y L. leucocephala cv. América), 5 (L. leucocephala cv. K-8 y K67) y 6 (L. leucocephala cv. Perú), (Tabla 1), concluyeron que, las biomasas comestibles de L. leucocephala cv. Cunningham, cv. América, cv. 7, cv. México, cv. CNIA-250y cv. K-28 presentaron las mejores características para la alimentación de rumiantes, por exhibir una adecuada composición proximal, menor cantidad de metabolitos secundarios y elevada degradabilidad de las fracciones nutritivas (Tabla 1). 
La inclusión de leucaena, para la alimentación de bovinos de leche, permitió reducir el uso de concentrado hasta en un $50 \%$ y lograr una mayor producción de leche, lo cual se le atribuye a un alto valor nutritivo de la leucaena, que suplió una fracción importante de los requerimientos proteicos y energéticos de las vacas. Se utilizó como dieta base guinea (Panicum maximum), king grass (Pennisetum purpureum x Pennisetum thiphoydes) (Rodríguez y Navarro, 2000).

Tabla 1. Composición nutricional de seis grupos cultivares de L. leucocephala

\begin{tabular}{lcccccc}
\hline \multicolumn{1}{c}{ Nutriente } & $\mathbf{1}$ & $\mathbf{2}$ & $\mathbf{3}$ & $\mathbf{4}$ & $\mathbf{5}$ & $\mathbf{6}$ \\
\hline Proteína cruda & 30.3 & 33.0 & 24.3 & 15.3 & 22.8 & 29.0 \\
FDN & 44 & 43.1 & 44.8 & 46.4 & 44.9 & 46.3 \\
FDA & 15.1 & 14.2 & 15.9 & 17.5 & 16.0 & 18.6 \\
Fibra cruda & 16.8 & 15.8 & 17.6 & 19.2 & 17.7 & 20.3 \\
Cenizas & 7.0 & 7.6 & 8.2 & 7.9 & 6.9 & 8.3 \\
DMS & 75.4 & 55.6 & 78.4 & 73.4 & 70.3 & 49.4 \\
DPC & 64.9 & 45.3 & 67.4 & 60.7 & 56.6 & 45.3 \\
DFDN & 56.2 & 36.7 & 58.0 & 52.1 & 50.1 & 45.7 \\
\hline
\end{tabular}

Fuente: García et al., 2008. DMS= Degradabilidad de la materia seca. DPC= Degradabilidad de la proteína cruda. DFDN= Degradabilidad de la fibra detergente neutro. $1=L$. leucocephala cv CNIA250 y K-28. $2=$ L. leucocephala cv Ipil-Ipil. $3=L$. leucocephala cv México. $4=L$. leucocephala cv Cunningham, L. leucocephala cv 7 y L. leucocephala cv América. $5=$ L. leucocephala cv K-8 y K-67 y $6=$ L. leucocephala cv Perú.

En una empresa pecuaria aún no se ha generalizado los sistemas silvopastoriles en sus áreas de pastoreo, debido a las desfavorables condiciones ecológicas y ambientales, lo que motiva la poca adaptación de las gramíneas, las leguminosas y los árboles forrajeros en estos suelos. Sí se implementa la explotación del cultivar como banco forrajero o como sistema de pastoreo-ramoneo, el incremento de solamente de un litro por vaca por día en 100 fincas con 40 vacas en ordeño significaría 4000 litros diarios más para esa empresa pecuaria. Es obvio, a partir de ese resultado, inferir las ventajas económicas y sociales por ese concepto, además, de las que se derivan de las mejoras ambientales directas, no 
cuantificadas, sobre la biodiversidad general, la reforestación y las propiedades hidrofísicas y bioquímicas del suelo, así como las indirectas que benefician el clima del ecosistema (Pentón, 2000; Osechas, 2002).

Pinto et al., (2000) en estudios con leucaena, respecto a la producción de leche, cuando se suplementó con esta leguminosa se elevó la cantidad de leche en dos litros (de 4 a 6) con relación con los animales que solo disponían de pastoreo. El follaje de $L$. leucocephala ha demostrado una alta calidad en términos de proteína cruda, energía, digestibilidad y palatabilidad, sí se compara con otros alimentos como la soya (Glycine max) y la alfalfa (Medicago sativa); además, tiene ventajas por su capacidad de rebrotar después de la poda o el ramoneo y que al adicionarla como suplemento de pastos de baja calidad y residuos de cosecha, incrementa el consumo y mejora la digestibilidad total de la dieta (Ruiz et al., 2001).

Godoy y Chicco, (2005) en experimentos con ovinos canulados en rumen, fueron sometidos a tres tratamientos con diferentes relaciones forraje/alimento concentrado: alta (forraje 100\%): mediana (forraje $50 \%$ y concentrado $50 \%$ ) y baja en forraje (forraje $20 \%$ y concentrado $80 \%$ ). Se utilizaron bolsas de nylon con forraje molido, para determinar la degradabilidad de la materia seca (MS), materia orgánica $(\mathrm{MO})$ y proteína (PC). No se observaron cambios aparentes en la degradación de la MS y MO. La proteólisis aumentó con la adición del concentrado, con valores más elevados $(P<0,05)$ para forraje $20 \%$ y concentrado $80 \%$. Se concluye que la suplementación con concentrados modifica los patrones de fermentación de las bacterias, aparentemente a favor de los microorganismos adaptados a condiciones más ácidas en el ambiente ruminal.

Otros estudios realizados por Razz et al., (2004) determinaron en la leucaena proteína cruda (PC) (26.8\%), FDN (42.6\%) y FDA (34.2\%), además, evaluaron en bovinos la degradabilidad in situ de la materia seca (MS) y la PC de este forraje, comparándolo con pasto guinea ( $P$. maximun) en diferentes horas $(6,12,24,48$ y 72), la mayor degradabilidad de la MS y de la $P C(P>0.05)$ la presentó el pasto 
(58.6 y $52.0 \%)$ VS (50.5 y $52.0 \%$ ), respectivamente, los autores argumentan que las degradaciones más reducidas de la leucaena se deben a la presencia de metabolitos secundarios fundamentalmente la mimosina, lo cual no concuerda con lo planteado anteriormente por Cruz, (1999).

\section{MATERIALES Y MÉTODOS}

Este proyecto se realizó en la universidad de los Llanos, ubicada en Villavicencio, la zona tiene un clima de bosque húmedo tropical con suelos de origen aluvial, tiene una altitud de 465 metros sobre el nivel del mar, temperatura promedio de 27 grados centígrados y precipitación anual entre 2500 a 4500 milímetros, temperatura promedio de $25^{\circ} \mathrm{C}$, humedad relativa entre $66 \%$ al $78 \%$.

Se utilizaron para este experimento 12 ovinos machos tipo africano (sudaneses) recién destetos con un peso promedio de $14.45 \mathrm{Kg}$, los cuales se vermifugaron y se mantuvieron en pastoreo con una dieta base de Braquiaria decumbens, agua y sal mineralizada ad-libitum. Los ovinos se distribuyeron en un diseño completamente al azar cuatro tratamientos con tres repeticiones. Los tratamientos fueron los siguientes T1 (testigo): braquiaria, sal y agua, T2: braquiaria, sal y agua más el $1 \%$ del peso vivo del animal, de materia seca (MS) de leucaena, T3: braquiaria, sal y agua más el $1.5 \%$ del peso vivo del animal, de MS de leucaena y T4: braquiaria, sal y agua más el $2.0 \%$ del peso vivo del animal, de MS de leucaena.

Los ovinos se mantuvieron en franjas divididas con cerca eléctrica y diariamente se rotaban, a cada tratamiento le correspondía una franja 166.5 metros cuadrados. Para calcular el consumo promedio por tratamiento, la franja se aforaba antes de entrar los animales, para valorar el pasto disponible para ese día, después de salir los animales de esa franja, se volvía aforar el potrero para determinar el pasto sobrante y por diferencia calcular el consumo de materia fresca por día. Los pesos de los ovinos se tomaron cada 7 días durante los dos meses que duro el trabajo de campo. 
En las pruebas de digestibilidad se utilizaron cuatro ovinos machos con un peso promedio de 15 kilos que se estabularon en jaulas metabólicas, y se les suministraron los mismos tratamientos con el fin de evaluar la digestibilidad in vivo de las dietas durante 13 días de acostumbramiento y 5 de recolección de la información.

Al pasto braquiaria y a la leucaena se les realizaron análisis proximal (materia seca proteína, grasa, fibra cruda, cenizas) y determinación de fibra detergente neutro (FDN) y fibra detergente ácido (FDA) (AOAC, 2006). A las excretas recolectadas durante cinco días también se realizaron los mismos a análisis de los forrajes. Con la información del análisis proximal se calcularon los coeficientes de digestibilidad (COD) y los nutrientes digestibles totales (NDT) Aplicando la formula $\%$ de NDT $=\% \mathrm{PC}^{*} \operatorname{cod}+\% \mathrm{FC}^{*} \operatorname{cod}+\% \mathrm{ENN}^{*} \operatorname{cod}+\%$ grasa ${ }^{*} \operatorname{cod}^{*} 2.25$. Agudelo (2001) y Church et al. (2002).

El trabajo de los cuatro ovinos en jaulas metabólicas fue distribuido por un diseño completamente al azar con cinco repeticiones y cuatro tratamientos, las variables fueron las digestibilidades de: Proteína, grasa, fibra cruda (FC), extracto no nitrogenado (ENN), FDN y FDA. El experimento en campo se realizó con 12 ovinos, distribuidos en un diseño completamente al azar con cuatro tratamientos y tres replicaciones, midiendo las variables de respuestas: consumo de alimento, aumento de peso y conversión alimenticia. Los análisis de varianza se realizaron por SPSS versión 15 y se hizo la comparación de medias aplicando la prueba de Tukey.

\section{RESULTADOS Y DISCUSIÓN}

Los análisis nutricionales de la leucaena y del braquiaria (Tabla 2) indican que la leucaena es una alternativa para suplementar a los ovinos en pastoreo con esta gramínea, puesto que el contenido de proteína de la leucaena es de $19.3 \%$, mientras que la del pasto es de $8.5 \%, 2.29$ veces más la de la leguminosa comparada con la del pasto. El extracto no nitrogenado (ENN), fibra cruda (FC) 
FDN y FDA fueron más altos en braquiaria en: $12.4 \%, 3.8 \%, 31.4 \%$ y $8.8 \%$ con relación a la leucaena, respectivamente.

Al comparar el contenido de PC, FDN y FDA encontrada por Cruz (1999) (25.6, 31.7 y $21.19 \%$, respectivamente con los resultados de esta investigación, se observa que la PC es menor en $6.3 \%$, mientras que FDN y FDA son mayores en $5.2 \%$ y 7.41 , respectivamente (Tabla 2 ), lo cual puede estar influenciado por muchos factores, principalmente: La genética y las condiciones ambientales.

Tabla 2. Composición nutricional (\%) de la leucaena y el Braquiaria

\begin{tabular}{lcc}
\hline \multicolumn{1}{c}{ Nutriente } & Leucaena & Braquiaria \\
\hline Materia seca & 36.9 & 28.8 \\
Proteína & 19.3 & 8.5 \\
Grasa & 2.7 & 1.4 \\
Fibra cruda & 22.7 & 26.5 \\
Cenizas & 8.4 & 8.3 \\
ENN & 32.9 & 45.3 \\
FDN & 36.9 & 68.3 \\
FDA & 28.6 & 37.4 \\
\hline
\end{tabular}

$\mathrm{ENN}=$ extracto no nitrogenado, $\mathrm{FDN}=$ fibra detergente neutro y $\mathrm{FDA}=$ fibra detergente ácido

En las investigaciones de García et al., (2008) donde se comparó seis cultivares de leucena, se puede deducir que los cultivares más similares en el contenido de proteína son: la 4 (L. leucocephala cv. Cunningham, L. leucocephala cv. 7 y L. leucocephala cv. América) (15.3\%) y 5 (L. leucocephala cv. K-8 y K-67) (22.4\%), con la de este trabajo (19.3\%) (Tablas 1 y 2). El contenido de FDN encontrado por estos autores es más alto en todos los cultivares de leucaena el cual que está entre 43.1 a $46.2 \%$, comparado con el analizado en este estudio (36.9\%), mientras que FDA y FC fueron más bajas (14.2 a 18.6\%) y (15.8\% a $20.3 \%$ ), respectivamente, al relacionarla con la de este trabajo, cuya FDA y FC fueron: 
22.7 y $28.6 \%$ respectivamente (Tablas 1 y 2 ). El contenido de cenizas fue similar en los dos estudios.

Referente a las digestibilidades de los nutrientes el de MS y proteína fueron superiores $(P>0.05)$ en los tratamientos T3 y T4, con relación a los otros dos tratamientos (Tabla 3). La digestibilidad de la grasa fue mayor $(P>0.05)$ en $T 1$, mientras que la digestibilidad de la FC, FDN y FDA fue más alta $(P>0.05)$ para T3 y T4, el porcentaje de nutrientes digestibles totales fue inferior $(P>0.05)$ para T1. Estos resultados indican que la leucaena mejora no solamente la calidad dieta sino, que también el aprovechamiento de estos nutrientes, debido a la formación de bacterias celulolíticas que ayudan a degradar la porción fibrosa de los forrajes. Lo que concuerda con Godoy y Chico, (2005) en lo relacionado que la suplementación en este caso con leucaena modifica los patrones de fermentación ruminal a favor de las bacterias celulolíticas que se adaptan a condiciones ligeramente ácidas en el ambiente ruminal (pH 5.5 a 6.8). Cruz, (1999) encontró que la leucaena tiene una degradabilidad de la materia seca de $80.3 \%$ muy similar a la digestibilidad de T4 (80.2\%) mientras que la degradabilidad del nitrógeno total fue de $52.2 \%$, lo cual es inferior a digestibilidad de la proteína de los cuatro tratamientos, evaluados en el presente experimento (Tabla 3 ).

Tabla 3. Digestibilidad (\%) de los nutrientes en los cuatro tratamientos

\begin{tabular}{lcccc}
\hline \multicolumn{1}{c}{ Nutriente } & T1 & T2 & T3 & T4 \\
\hline Materia seca & $72.7^{\mathrm{a}}$ & $73.2^{\mathrm{a}}$ & $80.2^{\mathrm{b}}$ & $79.7^{\mathrm{b}}$ \\
Proteína & $70.9^{\mathrm{a}}$ & $73.4^{\mathrm{a}}$ & $78.6^{\mathrm{b}}$ & $80.4^{\mathrm{b}}$ \\
Grasa & $57.9^{\mathrm{b}}$ & $47.9^{\mathrm{a}}$ & $50.1^{\mathrm{a}}$ & $49.5^{\mathrm{a}}$ \\
Fibra cruda & $59.2^{\mathrm{a}}$ & $77.9^{\mathrm{b}}$ & $82.8^{\mathrm{bc}}$ & $84.7^{\mathrm{c}}$ \\
ENN & $79.8^{\mathrm{a}}$ & $78.1^{\mathrm{a}}$ & $83.8^{\mathrm{b}}$ & $85.0^{\mathrm{b}}$ \\
FDN & $60.4^{\mathrm{a}}$ & $61.8^{\mathrm{a}}$ & $66.7^{\mathrm{b}}$ & $68.5^{\mathrm{b}}$ \\
FDA & $55.7^{\mathrm{a}}$ & $52.9^{\mathrm{a}}$ & $56.8^{\mathrm{ab}}$ & $58.4^{\mathrm{b}}$ \\
NDT & $60.7^{\mathrm{a}}$ & $63.9^{\mathrm{ab}}$ & $66.9^{\mathrm{b}}$ & $67.8^{\mathrm{b}}$ \\
\hline
\end{tabular}

$\mathrm{Tl}=$ Braquiaia, $\mathrm{T} 2=$ Braquiaria $+1 \%$ leucaena, $\mathrm{T} 3=$ Braquiaria $+1.5 \%$ leucaena, y $\mathrm{T} 4=$ Braquiaria + $2.0 \%$ leucaena, $\mathrm{MS}=$ Materia seca, FDN= Fibra detergente neutro, FDA= Fibra detergente ácido, y $\mathrm{NDT}=$ Nutrientes digestibles totales. Letras diferentes en la misma fila son diferentes $(P<0.05)$. 
Las ganancias de peso total y diaria fueron superiores $(P>0.05)$ para T3 seguido de T4 y T2 que son mayores $(P>0.05)$ a T1 (Tabla 4 y Gráficas 1 y 2). Los consumos de materia seca total fueron más elevados $(P>0.05)$ T1 y T4 en comparación con T3 y T2 (Tabla 1, Gráficas 3, 4 y 5). La mejor conversión alimenticia $(P>0.05)$ sobre el consumo total de la materia seca fue para T3 seguido de T2, T4 y T1, siendo todas diferentes (Tabla 4). Analizando estos resultados, se pude afirmar que al suplementar los ovinos con más del $1.5 \%$ de leucaena en pasto braquiaria se redujo $(P>0.05)$ su ganancia de peso y su conversión alimenticia, es posible que los metabolitos secundarios como la mimosina, afecten el aprovechamiento de los nutrientes destinados a la producción de carne, a nivel de metabolismo, puesto que las digestibilidades de la materia seca fueron similares para T3 y T4, ósea para los niveles de $1.5 \%$ y $2 \%$ de leucaena.

Tabla 4. Comportamiento productivo de los ovinos africanos en los cuatro tratamientos

\begin{tabular}{lcccc}
\hline \multicolumn{1}{c}{ Parámetros } & T1 & T2 & T3 & T4 \\
\hline Días de experimentación & 60 & 60 & 60 & 60 \\
Peso inicial $(\mathrm{Kg})$ & 14.2 & 14.9 & 14.4 & 14.3 \\
Peso final $(\mathrm{Kg})$ & $23.1^{\mathrm{a}}$ & $27.2^{\mathrm{b}}$ & $31.7^{\mathrm{c}}$ & $27.1^{\mathrm{b}}$ \\
Ganancia de peso total $(\mathrm{Kg})$ & $9.66^{\mathrm{a}}$ & $12.3^{\mathrm{b}}$ & $17.3^{\mathrm{c}}$ & $12.8^{\mathrm{b}}$ \\
Ganancia diaria de peso (Kg) & $0.161^{\mathrm{a}}$ & $0.205^{\mathrm{b}}$ & $0.289^{\mathrm{c}}$ & $0.214^{\mathrm{b}}$ \\
Consumo de pasto fresco /día (Kg) & $2.81^{\mathrm{c}}$ & $1.89^{\mathrm{b}}$ & $1.69^{\mathrm{a}}$ & $1.68^{\mathrm{a}}$ \\
Consumo de pasto seco /día (Kg) & $1.042^{\mathrm{c}}$ & $0.697^{\mathrm{b}}$ & $0.623^{\mathrm{a}}$ & $0.622^{\mathrm{a}}$ \\
Consumo de Leucaena fresca por día (kg) & 00 & $0.717^{\mathrm{a}}$ & $1.21^{\mathrm{b}}$ & $1.44^{\mathrm{c}}$ \\
Consumo de Leucaena seca por día (kg) & $00^{\mathrm{a}}$ & $0.207^{\mathrm{b}}$ & $0.348^{\mathrm{c}}$ & $0.416^{\mathrm{d}}$ \\
Consumo total de MS /día (Kg) & $1.042^{\mathrm{c}}$ & $0.904^{\mathrm{a}}$ & $0.971^{\mathrm{b}}$ & $1.040 \mathrm{c}$ \\
Conversión con relación al consumo de MS & $6.47^{\mathrm{c}}$ & $4.41^{\mathrm{b}}$ & $3.36^{\mathrm{a}}$ & $4.86^{\mathrm{c}}$ \\
Eficiencia alimenticia (\%) & $15.5^{\mathrm{a}}$ & $22.7^{\mathrm{b}}$ & $29.8^{\mathrm{c}}$ & $20.6^{\mathrm{a}}$ \\
\hline
\end{tabular}

$\mathrm{T} 1=$ Braquiaia, $\mathrm{T} 2=$ Braquiaria $+1 \%$ leucaena, $\mathrm{T} 3=$ Braquiaria $+1.5 \%$ leucaena, y $\mathrm{T} 4=$ Braquiaria + $2.0 \%$ leucaena, $M S=$ Materia seca. Letras diferentes en la misma fila son diferentes $(P<0.05)$. 

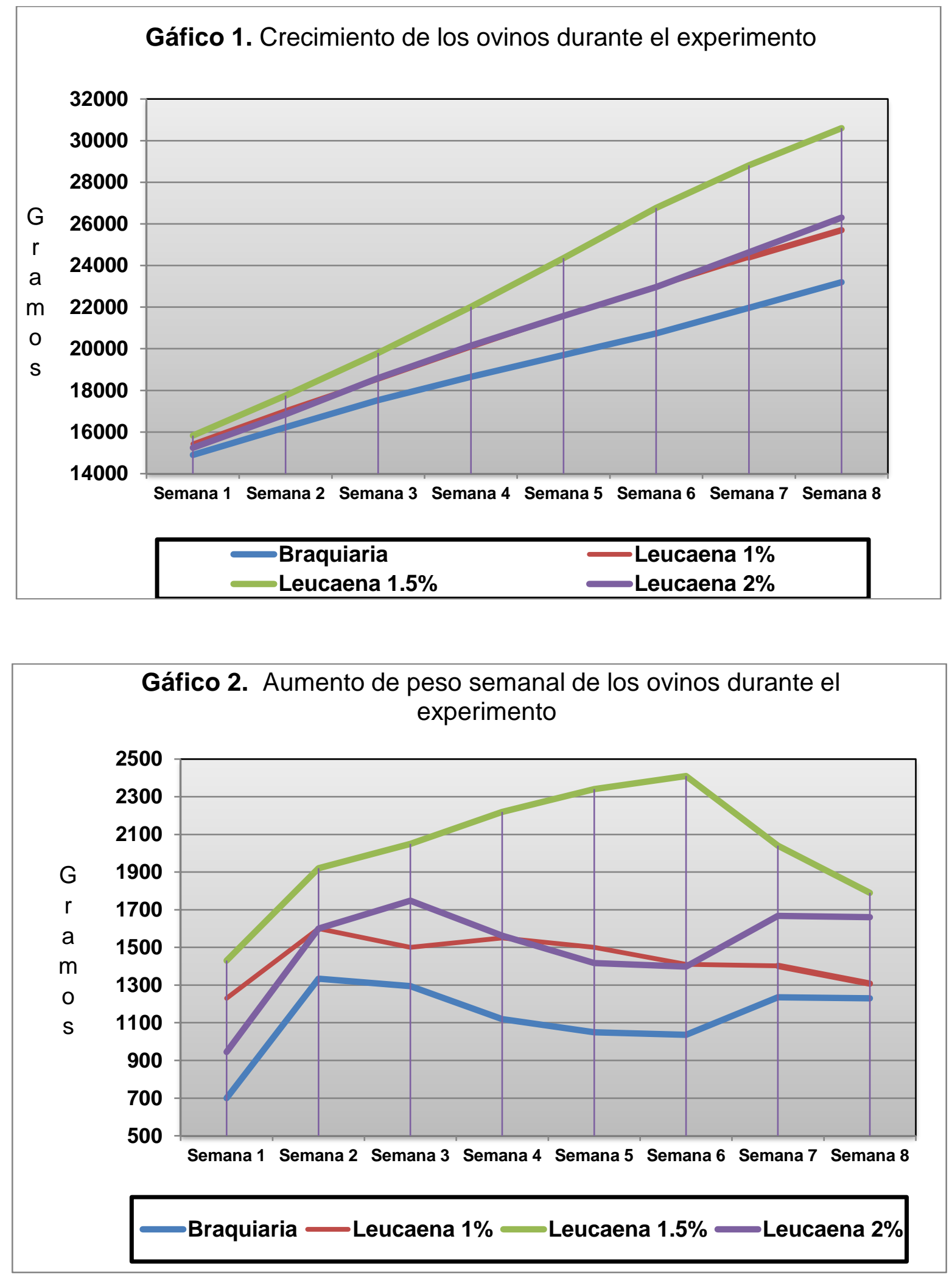

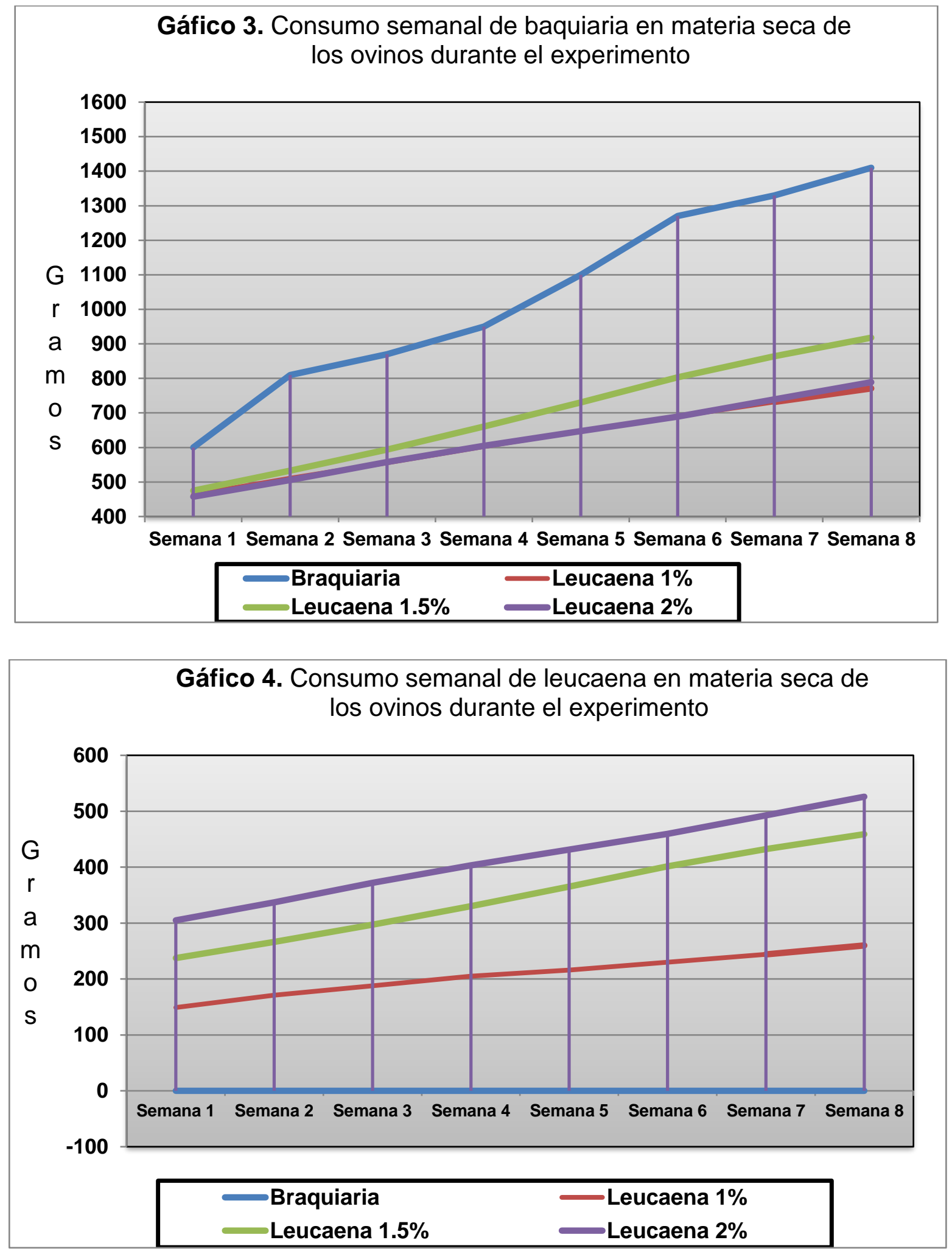


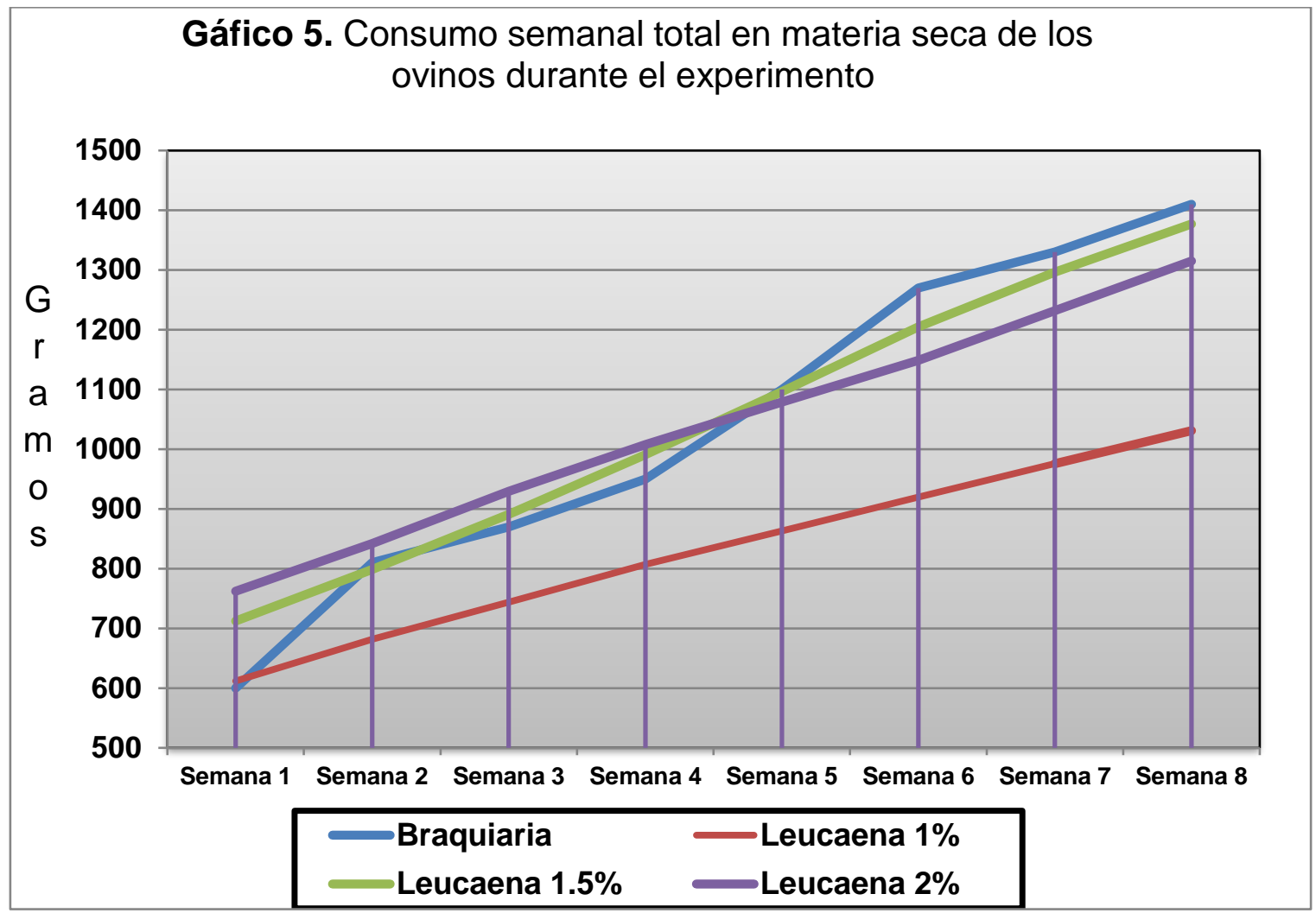

Indudablemente, utilizar la leucaena, para la alimentación de rumiantes como suplemento de una gramínea es ventajoso porque su contenido nutricional le permite ofrecer una dieta balanceada al animal sin detrimento de sus índices productivos, esto concuerda, con lo que reportan Rodríguez y Navarro, (2000) y Pinto et al., (2000) quienes mencionan que la leucaena, puede incrementar la producción de leche, y en otros casos reemplazar el concentrado hasta en un 50\% en vacas lecheras en pastoreo.

El consumo de materia seca fue más alto para $\mathrm{T} 1$ y $\mathrm{T} 4$, pero fueron los de más baja conversión alimenticia (Tabla 4). En T1, el pasto braquiaria no cubre las necesidades nutricionales, principalmente debido a su contenido de proteína de (8.5\%), pero en el T4, la influencia en este resultado se debe a la presencia posiblemente a factores antinutricionales de la leguminosa (mimosina) que al unirse a los de pasto (taninos) pueden tener un efecto negativo sobre la eficiencia 
alimenticia, tal como se demuestra en la curva de crecimiento (Tabla 4 y Gráficas 1 y 2).

El aumento de peso en T2 fue incrementando las seis primeras semanas y después decreció, lo cual se debe a que los animales adultos no crecen con la misma tasa que los animales jóvenes, este comportamiento fue similar para T2, los otros dos tratamientos la tasa de crecimiento hizo fluctuaciones durante las 7 semanas, únicamente se observó un alto incremento en la primera semana (Gráfica 2).

\section{CONCLUSIONES Y RECOMENDACIONES}

La leucaena por su contenido de proteína $19.3 \%$, se puede utilizar como suplemento (hasta $1.5 \%$ del peso vivo), en ovinos pastoreando braquiaria, mejorando su peso y conversión alimenticia. Con un mayor porcentaje de leucaena (2\%), en los ovinos se observa un comportamiento similar de estos factores a los animales que están solo pastoreo.

Al comparar el contenido de proteína, FDN y FDA con los investigados en otros estudios se diferencia, siendo más baja la proteína evaluada en este trabajo, lo que indica que diferentes ecotipos de leucaena, tienen diferente composición nutricional.

Las digestibilidades de la materia seca y proteína cruda son más elevadas $(P>0.05)$ en T3 y T4 en comparación con los otros dos tratamientos. Se recomienda seguir investigando para determinar el ecotipo que más se adapte a los suelos ácidos de esta región del Piedemonte llanero.

\section{REFERENCIAS BIBLIOGRÁFICAS}

1. Agudelo G. Fundamentos de nutrición aplicada. Ed. Ciencia y tecnología Universidad de Antioquia. 1ed: 13-20. Medellín, Colombia. 2001. 
2. AOAC. Official Methods of Analysis $\left(18^{\text {th }}\right)$ Association of Official Analytical Chemists, Arligton, VA. Washington, D.C. 2006.

3. Cárdenas M. Comportamiento productivo de vacas lactantes de doble propósito, mantenidas bajo dos cargas de pastoreo con o sin suplemento de follaje de L. leucocephala. Tesis de Licenciatura Facultad de Medicina Veterinaria y Zootecnia. Mérida, Yucatán. 2000.

4. Church D. C., Pond W., Pond K. Fundamentos de Nutrición y Alimentación de animales. Ed. Uthea Wiley. $2^{\circ}$ ed: p 57-72. México. 2002.

5. Cruz M. W. Comportamiento agronómico y calidad nutritiva de especies de leucaena en el estado de Yucatán. Tesis de Maestría Facultad de Medicina Veterinaria / UADY. Mérida Yucatán. 1999.

6. García D, Wencomo H. Gonzáles M., Medina M., Cova L. Caracterización de diez cultivares forrajeros de Leucaena leucocephala basada en la composición química y la degradabilidad ruminal. Rev. MVZ Córdoba 13 (2): 1294 - 1303. 2008.

7. Godoy S., Chicco C. F. Actividad fitásica in vitro de los microorganismos del rumen y degradación in situ de un sustrato fibroso en ovinos alimentados con diferentes regímenes. Zootecnia Tropical, 23 (1): 61- 68. 2005.

8. Ibrahim M., Villanueva C., Casasolo F. Sistemas silvopastoriles para el mejoramiento de paisajes ganaderos. Arch. Latinoam. de Prod. Anim. 15 (1): 77 - 89. 2007.

9. Mármol F. J. Manejo de pastos y forrajes en la ganadería doble propósito. En: $X$ Seminario Manejo y Utilización de pastos y forrajes en Sistemas de Producción Animal. Editor Rony Tejos. Fundapastos. Guanare. Venezuela. pp. 1 - 9. 2006.

10. Osechas D. Caracterización forrajera en fincas del estado Trujillo. Revista Científica LUZ XII (2): 559 - 561. 2002.

11. Osechas D., Becerra L., Torres A. Interrelación de estrategias usadas en el manejo y aprovechamiento de pastizales en fincas del estado Trujillo. Rev. Fac. Agron. 23 (3): 338 - 348. 2006. 
12. Osechas O, Becerra L y Rodríguez I. Uso de Leucaena leucocephala como recurso forrajero en fincas doble propósito del estado Trujillo. Venezuela Mundo Pecuario, IV, № 1, 38 - 45. 2008.

13. Pérez A., Wencomo H, Navarro M, Iglesias J. M, Soca M, Cepero L., Canchila E. R. Consideraciones acerca de la Leucaena leucocephala cv. X: una nueva opción forrajera para un ecosistema ganadero con suelos ácidos e infértiles. Pastos y Forrajes, Matanzas, V 31: 10 p. 2008.

14. Pentón G. Nota técnica: Tolerancia del Panicum maximum cv. Likoni a la sombra en condiciones controladas. Pastos y Forrajes. 23: 79. 2000.

15. Pinto R.; Ramírez-Avilés L.; Ku-Vera J. C.; Hernández A.; Sánchez F., Saucedo H. Evaluación químico-nutricional y degradabilidad ruminal de especies arbóreas del centro de Chiapas, México. Memorias IV Taller Internacional Silvopastoril «Los Árboles y arbustos en la ganadería tropical». EEPF “Indio Hatuey”. Matanzas, Cuba. p. 47. 2000.

16. Razz R., Clavero T., Vergara J. Cinética de degradación in situ de la Leucaena leucocephala y Panicum maximum. Revista Científica FCV-LUZ. XIV (5): 424 - 430. 2004.

17. Razz R., Clavero T. Cambios en las características químicas de suelos en un banco de Leucaena leucocephala y en un mono cultivo de Brachiaria brizantha. Rev. Fac. Agron, LUZ 23 (3): 331 - 337. 2006.

18. Rodríguez T., Navarro L. Aspectos nutricionales a considerar en el manejo de algunas gramíneas forrajeras en los llanos orientales de Venezuela. En: Establecimiento, manejo y recuperación de pasturas en sabanas bien drenadas. Publicación especial № 38. FONAIAP, Anzoátegui, Venezuela. pp. 58-67. 2000.

19. Rodríguez J., Valero Y. Importancia nutricional de Leucaena leucocephala en la producción animal. En: VIII Seminario manejo y utilización de pastos y forrajes en sistemas de producción animal. 14-16 de marzo. Edit. UNELLEZ. Barinas, Venezuela. pp. 1-13. 2002. 
20. Ruiz T. E.; Febles G.; Díaz J. A.; Díaz H., Díaz L. E. La poda: una labor necesaria en Leucaena leucocephala para los sistemas silvopastoriles. Memorias. IV Taller Internacional Silvopastoril "Los árboles y arbustos en la ganadería tropical". EEPF "Indio Hatuey". Matanzas, Cuba. p. 233. 2001.

21. Sosa R. E, Haggar J., Zapata B. G. Manual agrofrorestal de la península de Yucatán. Haggar (ed) Inifap / Icraf / Fundación Quintana Roo Produce, Chetamal Quintana Roo, México. 1999. 